\title{
Placebo-Controlled Discontinuation of Long-Term Acid-Suppressant Therapy: A Randomised Trial in General Practice
}

\author{
Jon Eik Zwisler, ${ }^{1}$ Dorte Ejg Jarbøl, ${ }^{1}$ Annmarie Touborg Lassen, ${ }^{2}$ Jakob Kragstrup, ${ }^{3}$ \\ Niels Thorsgaard, ${ }^{4}$ and Ove B. Schaffalitzky de Muckadell ${ }^{5}$ \\ ${ }^{1}$ Research Unit of General Practice, Department of Public Health, University of Southern Denmark, \\ J. B. Winslows Vej 9A, Odense, Denmark \\ ${ }^{2}$ Department of Emergency Medicine, Odense University Hospital, 5000 Odense, Denmark \\ ${ }^{3}$ Research Unit for General Practice and Section of General Practice, Department of Public Health, Copenhagen University, \\ 1014 Copenhagen K, Denmark \\ ${ }^{4}$ Department of Internal Medicine, Regional Hospital Herning, 7400 Herning, Denmark \\ ${ }^{5}$ Department of Medical Gastroenterology, Odense University Hospital, 5000 Odense, Denmark
}

Correspondence should be addressed to Dorte Ejg Jarbøl; djarbol@health.sdu.dk

Received 11 March 2015; Revised 22 June 2015; Accepted 29 June 2015

Academic Editor: Paul Van Royen

Copyright (c) 2015 Jon Eik Zwisler et al. This is an open access article distributed under the Creative Commons Attribution License, which permits unrestricted use, distribution, and reproduction in any medium, provided the original work is properly cited.

Objective. To investigate whether patients on long-term antisecretory medication need to continue treatment to control symptoms. Methods. A double-blinded randomised placebo-controlled trial in general practices in Denmark. Patients aged 18-90 who were treated with antisecretory drugs on a long-term basis were randomized to esomeprazole $40 \mathrm{mg}$ or identical placebo. Outcome measures were time to discontinuation with trial medication due to failed symptom control analysed as survival data. The proportion of patients stopping trial medication during the one-year follow-up was estimated. Results. A total of 171 patients were included with a median prior duration of antisecretory treatment of four years (range: 0.5 to 14.6 years). 86 patients received esomeprazole $40 \mathrm{mg}$ and 85 patients received placebo. At 12 months, statistically significantly more patients in the placebo group had discontinued $(73 \%(62 / 85))$ compared with the esomeprazole group $(21 \%(18 / 86) ; p<0.001)$. Conclusions. Long-term users of antisecretory drugs showed a preference for the active drug compared to placebo. However, $27 \%$ of patients continued on placebo throughout the study and did not need to reinstitute usual treatment. One in five patients treated with esomeprazole discontinued trial medication due to unsatisfactory symptom control. Discontinuation of antisecretory treatment should be considered in longterm users of antisecretory drugs. This trial is registered with Trial registration ClinicalTrials.gov ID: NCT00120315.

\section{Introduction}

The use of acid-suppressive medication is rapidly increasing. In the western world, proton pump inhibitors (PPIs) are second only to statins in expenditures, and antisecretory medication constitutes a substantial part of the medical budget in the Denmark and other western countries [1-3]. Most of the increased use of antisecretory medication is accounted for by long-term users $[4,5]$.

Antisecretory medication is highly effective for the treatment of peptic ulcer and reflux disease, but it has only sparse effect in the treatment of patients with functional dyspepsia [6]. In primary care, the most used strategy when investigating and treating dyspeptic patients is empirical treatment with antisecretory drugs [7]. As no data exist regarding the optimal treatment period, and as there is a poor correlation between initial treatment response and continued effect, some patients might have an unnecessary continued use of antisecretory medication [8]. In a Swedish study, Björnsson et al. [9] found that discontinuation of antisecretory mediation was successful in $27 \%$ of long-term users of PPI. Placebo-controlled discontinuation studies of antisecretory medication with interventions carried out in primary care are however not yet published. 
The aim of the present study was therefore in a placebocontrolled randomised design to investigate if patients on long-term antisecretory medication need to continue treatment to control symptoms in a primary care setting.

\section{Methods}

2.1. Protocol. A total of 146 general practitioners in Denmark were visited, introduced to, and educated in study procedures and signed in as coinvestigators on the required forms from the Danish Medicines Agency (Protocol ID: 2612-2176). Eligible patients were evaluated, enrolled, and followed by their general practitioner from January 2003 to September 2006.

2.2. Assignment. Patients older than 17 years with a use of antisecretory treatment (proton pump inhibitors or histamine-2-receptor-antagonists) for at least 56 days during the previous six months were included. Exclusion criteria were alarm symptoms (gastrointestinal bleeding, iron deficiency anemia, progressive unintentional weight loss, progressive dysphagia, persistent vomiting, and epigastric mass on palpation), drug or alcohol abuse, serious or terminal diseases, planned hospitalization during follow-up, allergy to trial medication, and pregnant or fertile females not using safe contraception. Furthermore, patients suffering from oesophagitis, having had prior complicated peptic ulcer, and patients with prior endoscopically verified ulceration and ongoing use of nonsteroidal anti-inflammatory drugs (NSAIDs)/acetylic salicylic acid (ASA) were not eligible.

2.3. Interventions. Long-term users of antisecretory treatment were randomised to continued antisecretory treatment or placebo. Esomeprazole (Nexium, AstraZeneca) $40 \mathrm{mg}$ or identical placebo was used as the randomised trial medication with a maximum of one tablet a day mimicking the patient's usual treatment. When trial medication was discontinued due to insufficient symptom control, reinstitution of usual antisecretory treatment was left to the GPs' discretion.

2.4. Masking. Both active medication and placebo were manufactured and packed by AstraZeneca, Mölndal, Sweden, in accordance with Good Manufactory Practice (GMP). Trial drug was delivered in identical, sealed containers holding 100 tablets. The local university hospital pharmacy (Fyns Amts Centralapotek, J. B. Winsløws Vej 13, DK-5000 Odense C, Denmark) labelled and randomised the trial drug accordingly using a computer-generated random number block randomisation with a fixed block size of four and a placebo/treatment ratio of one. The pharmacy kept the sequence of allocation concealed throughout the one-year follow-up, thus blinding patients, general practitioners, and researchers. Following seven days of discontinuation of usual antisecretory treatment with allowance of antacids as rescue treatment, Helicobacter pylori status was investigated with a ${ }^{13} \mathrm{C}$-urea breath test performed in general practice. During the seven days of discontinuation symptoms, demographics and clinical baseline characteristics of participants were obtained. Eradication therapy was given to any Helicobacterpositive patient (amoxicillin, clarithromycin, and esomeprazole, alternatively metronidazole if allergic to penicillin). The study was monitored according to Good Clinical Practice (GCP) by the GCP unit at Odense University Hospital, Denmark (Project number 02-004).

2.5. Outcomes. Primary endpoint was the time to discontinuation with trial medications (esomeprazole or placebo) due to the participants' need to change back to their usual antisecretory medication, that is, failure to control symptoms with the trial medication at any time point in the one-year follow-up. The proportion of patients stopping trial medication during the one-year follow-up was estimated. Additional analysis was carried out using health-related quality-of-life (MOS Short Form-36) [10] and generic dyspeptic quality-of-life (gastrointestinal symptom rating scale) [11] questionnaires.

2.6. Sample Size and Analysis. We assumed 15-20\% of longterm users to be suffering from peptic ulcer disease, 40$45 \%$ to be suffering from nonerosive reflux disease, and approximately $40 \%$ to be suffering from functional dyspepsia [12]. Based on these diagnoses, we estimated the recurrence of symptoms in $10 \%$ in the esomeprazole group and $30 \%$ in the placebo group and given a type I error of $5 \%$ and a type II error of $20 \%$ at least 111 patients in each group were needed.

During data analysis, patients remained in the two arms of the study without revealing the intervention, thus allowing a blinded data analysis of the primary endpoint [13]. Primary outcome was assessed using survival data analysis. An intention to treat analysis was performed. Assumptions that dropouts in both groups had insufficient control of symptoms and therefore were analysed as having stopped with trial medication were made.

\section{Results}

3.1. Participant Flow and Follow-Up. A total of 171 patients found eligible by their general practitioners were accepted to participate in the study (Figure 1); $17 \%$ were Helicobacter pylori-positive. During the one-year follow-up, six patients were lost to follow-up; no adverse events were seen, except for one patient developing a black discoloration of the tongue during Helicobacter pylori eradication treatment. Characteristics at baseline are shown in Table 1. No differences were found between GPs not including participants compared with active coinvestigators with regard to sex, single-handed or partnership practice, and number of long-term users, data not shown.

3.2. Analysis. At the one-year follow-up, the stop of the trial medication had occurred more frequently $(p<0.0001$, log-rank) in the placebo group compared with the group receiving esomeprazole. A total of 18/86 (21\%) of participants treated with esomeprazole had stopped the trial medication compared to $62 / 85(73 \%)$ of participants treated with placebo (Figure 2). Gastrointestinal symptom scores improved in both groups during the trial, but no statistically significant 


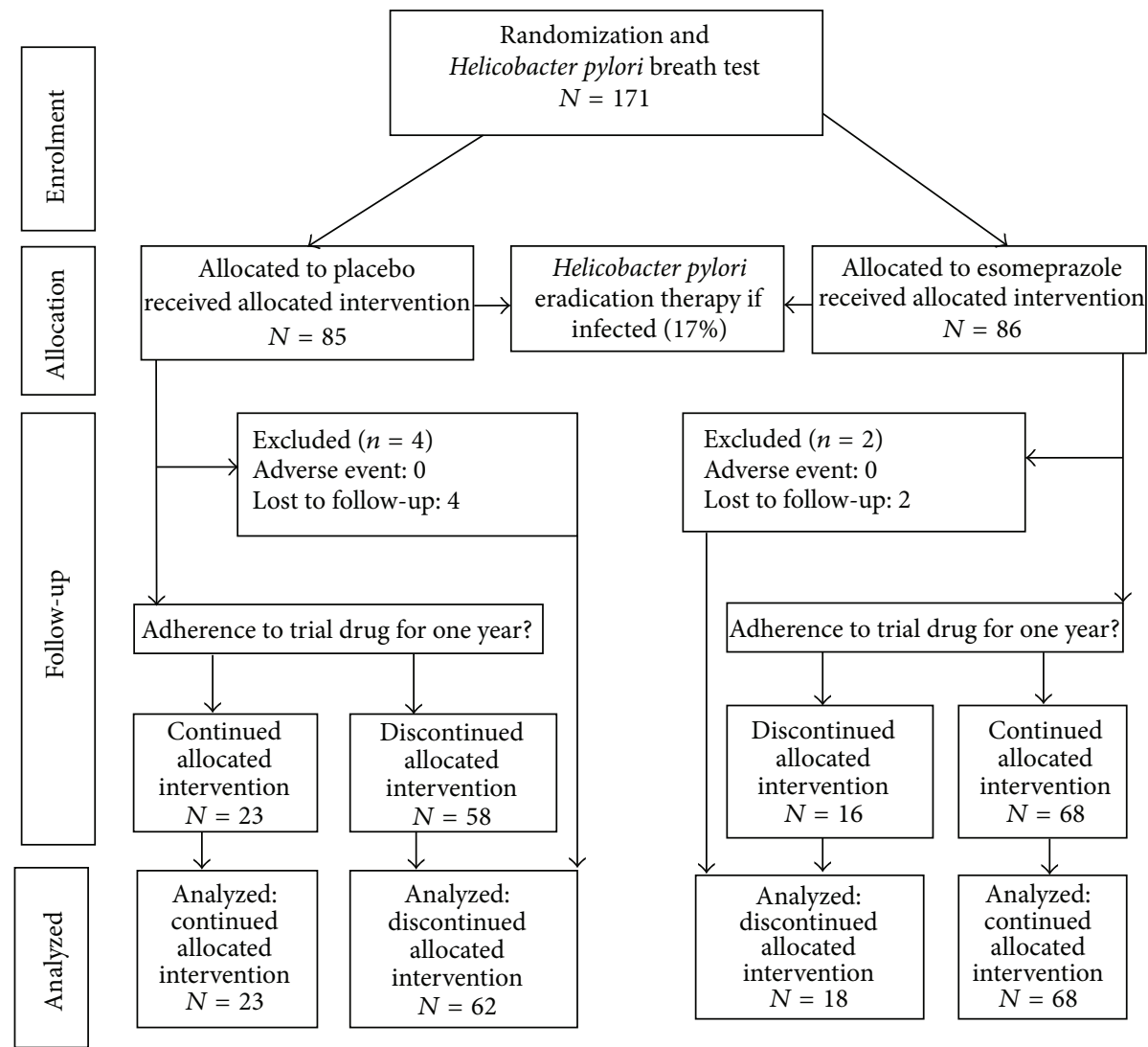

FIgURE 1: Flow of participants through study.

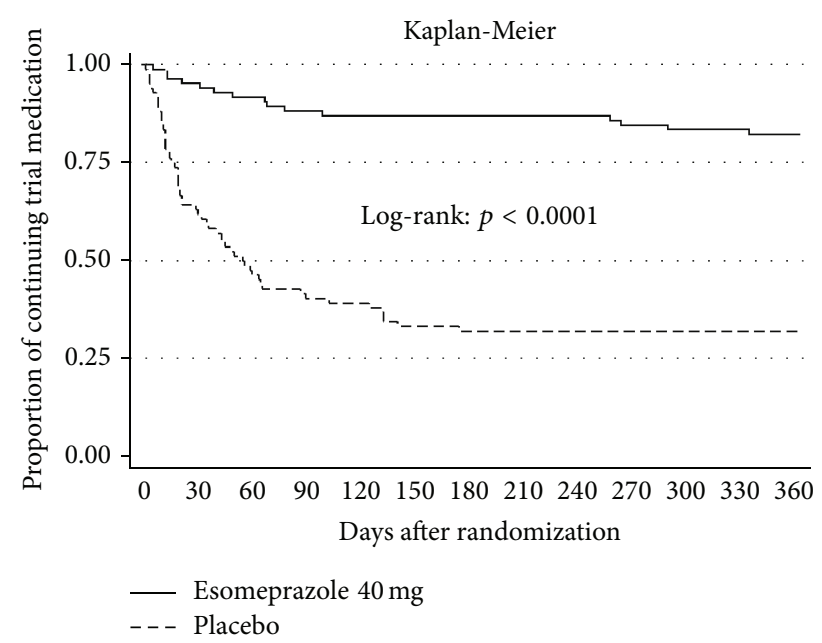

FIgURE 2: Discontinuation of trial medication in 1-year follow-up.

differences were found between the two groups after one year (Table 2). Quality-of-life scores were unchanged, and no differences were found between groups after one year (data not shown).

Table 3 shows a comparison between patients continuing placebo versus patients who stopped treatment with placebo. Statistically significantly more men stopped placebo
TABle 1: Demographics and clinical baseline characteristics of participants.

\begin{tabular}{|c|c|c|}
\hline & $\begin{array}{l}\text { Placebo } \\
N=85\end{array}$ & $\begin{array}{c}\text { PPI* }^{*} \\
N=86\end{array}$ \\
\hline Male (\%) & $37(44)$ & $41(48)$ \\
\hline $\begin{array}{l}\text { Age, median }(10 \%-90 \% \\
\text { percentile), year }\end{array}$ & $59(39-79)$ & $59(39-77)$ \\
\hline Smoking, $n(\%$; 95\% CI) & $31(36 ; 26-48)$ & $39(45 ; 35-56)$ \\
\hline $\begin{array}{l}\text { Alcohol use, }<21 \text { units/weeks } n \\
(\% ; 95 \% \text { CI })\end{array}$ & $79(93 ; 85-97)$ & $79(92 ; 84-97)$ \\
\hline $\begin{array}{l}\text { Symptom duration, median } \\
\text { (10\%-90\% percentile), year }\end{array}$ & $4(1-16)$ & $4(1-13)$ \\
\hline $\begin{array}{l}\text { Helicobacter pylori-positive } n(\% ; \\
95 \% \text { CI) }\end{array}$ & $12(14 ; 7-23)$ & $17(20 ; 12-30)$ \\
\hline $\begin{array}{l}\text { Previous endoscopy, } n(\% ; 95 \% \\
\text { CI) }\end{array}$ & $46(54 ; 42-64)$ & $39(45 ; 34-56)$ \\
\hline $\begin{array}{l}\text { Previous NSAID/ASA use, } n(\% \text {; } \\
95 \% \text { CI })\end{array}$ & $52(61 ; 49-71)$ & $53(61 ; 50-72)$ \\
\hline
\end{tabular}

treatment during follow-up ( $p=0.003)$. A statistically nonsignificant tendency towards a more successful continuation with placebo treatment was found for patients with less gastrointestinal symptoms (total GSRS score, $p=0.07$ ). The subscore regarding reflux symptoms (heartburn and 
TABLE 2: Gastrointestinal symptoms at baseline and after 1 year according to randomization group.

\begin{tabular}{|c|c|c|c|c|c|}
\hline \multirow{3}{*}{$\begin{array}{l}\text { Gastrointestinal symptom } \\
\text { rating scale, median (IQR) }\end{array}$} & \multicolumn{2}{|c|}{ Baseline } & \multicolumn{2}{|c|}{1 year } & \multirow{3}{*}{$p$ value $^{\ddagger}$} \\
\hline & Placebo & PPI* & Placebo & PPI* & \\
\hline & $N=85$ & $N=86$ & $N=69$ & $N=79$ & \\
\hline Total score & $2.6(2.4 ; 2.8)$ & $2.5(2.3 ; 2.7)$ & $1.9(1.7 ; 2.1)$ & $1.8(1.7 ; 2.0)$ & 0.73 \\
\hline Abdominal pain & $2.7(2.4 ; 3.0)$ & $2.6(2.4 ; 2.8)$ & $2.0(1.8 ; 2.3)$ & $1.8(1.6 ; 2.0)$ & 0.58 \\
\hline Reflux & $3.2(2.8 ; 3.5)$ & $3.1(2.7 ; 3.4)$ & $1.8(1.6 ; 2.0)$ & $1.8(1.6 ; 2.0)$ & 0.74 \\
\hline Indigestion & $3.1(2.8 ; 3.3)$ & $3.0(2.7 ; 3.2)$ & $2.2(2.0 ; 2.5)$ & $2.2(1.9 ; 2.4)$ & 0.83 \\
\hline Diarrhea & $2.2(1.9 ; 2.5)$ & $1.9(1.6 ; 2.1)$ & $1.6(1.4 ; 1.8)$ & $1.5(1.3 ; 1.7)$ & 0.48 \\
\hline Constipation & $2.2(1.9 ; 2.5)$ & $2.0(1.7 ; 2.3)$ & $1.8(1.5 ; 2.0)$ & $1.7(1.5 ; 2.0)$ & 0.88 \\
\hline
\end{tabular}

* Esomeprazole $40 \mathrm{mg}$.

${ }^{\dagger}$ Gastrointestinal symptom rating scale. Range 1-7. Increasing values reflect increasing symptoms.

${ }^{\ddagger}$ Between group comparison. Difference in GSRS score at entry versus one year. Conditional linear regression adjusted for GP clusters.

TABLE 3: Associations with discontinuation in placebo group $(n=85)$.

\begin{tabular}{|c|c|c|c|}
\hline & $\begin{array}{l}\text { Successful discontinuation } \\
\text { (continuing placebo) } \\
(n=23)\end{array}$ & $\begin{array}{c}\text { Unsuccessful discontinuation } \\
\text { (discontinuing placebo) } \\
(n=62)\end{array}$ & $p$ value $^{*}$ \\
\hline Age median (IQR), year & $58(48-62)$ & $60(51-69)$ & 0.81 \\
\hline Male (\%) & $23 \%$ & $58 \%$ & 0.003 \\
\hline Helicobacter pylori-positive, \% (95\% CI) & $29(12-51)$ & $17(8-29)$ & 0.24 \\
\hline No nicotine use, $\%$ (95\% CI) & $68(46-85)$ & $50(37-63)$ & 0.12 \\
\hline Alcohol use, $<21$ units/weeks, \% (95\% CI) & $92(74-99)$ & $92(82-97)$ & 0.96 \\
\hline $\begin{array}{l}\text { Symptom duration, median (10\%; } 90 \%) \\
\text { percentile, year }\end{array}$ & $4(0-13)$ & $4(1-14)$ & 0.21 \\
\hline Previous endoscopy, \% (95\% CI) & $40(21-61)$ & $47(24-60)$ & 0.58 \\
\hline Previous NSAID/ASA use, $\%$ (95\% CI) & $60(39-79)$ & $62(48-74)$ & 0.89 \\
\hline GSRS total, mean $(95 \% \mathrm{CI})$ & $2.5(2.2-2.8)$ & $2.9(2.5-3.2)$ & 0.07 \\
\hline GSRS reflux score, mean (95\% CI) & $3.0(2.5-3.5)$ & $3.3(2.9-3.8)$ & 0.29 \\
\hline $\begin{array}{l}\text { SF-36 physical health summary score, mean score } \\
(95 \% \mathrm{CI})\end{array}$ & $41(36-46)$ & $43(40-46)$ & 0.54 \\
\hline $\begin{array}{l}\text { SF-36 mental health summary score, mean score } \\
(95 \% \mathrm{CI})\end{array}$ & $48(42-54)$ & $51(49-54)$ & 0.20 \\
\hline
\end{tabular}

${ }^{*} F$-test for linear regression.

regurgitation) did, however, show less influence on continued placebo treatment $(p=0.29)$.

\section{Discussion}

The present study provides estimates from primary care on the need for continued antisecretory treatment among long-term users. In a randomised, placebo-controlled trial, long-term users of antisecretory treatment were randomised to either continued antisecretory treatment (esomeprazole $40 \mathrm{mg}$ ) or placebo. We found that $27 \%$ of participants receiving placebo did not stop the trial medication during the complete follow-up.

To our knowledge, this study was the first nonindustry initiated drug trial conducted in a primary care setting, which was GCP monitored by a public GCP unit. The randomised design and blinding in the design hindered any contamination between participants in the same practice and allowed a blinded data analysis. The primary care setting is important as $90 \%$ of antisecretory drugs are prescribed in primary care [14] and the findings may be applicable to patients managed in primary care in similar settings.

Recruitment of patients for the study tended to be slower than expected and only 38\% of the coinvestigators (GPs) recruited participants for the study. No differences were, however, found between GPs not including participants compared with active coinvestigators.

Based on register data [15], a large group of persons met the definition of long-term use of antisecretory treatment [4], but only a minority of the persons was included in this particular study. However, the register data do not provide information about indications for the prescription of antisecretory medication and some of the persons in the registers were probably meeting one or more of the exclusion criteria defined for the study. However, we cannot rule out the possibility that some of the persons, who were not included, had already tried to discontinue their antisecretory treatment.

Due to the absence of consensus on the optimal treatment duration, the design of a discontinuation study was chosen and the discontinuation of trial drug was the primary 
outcome measure. The fluctuation of dyspepsia symptoms is well known and severity as well as symptoms may vary in the same patient over time [16]. This may give rise to reflections on whether disappearance of symptoms due to the natural history of symptom fluctuation would allow participants receiving placebo to continue the trial drug. However, discontinuation of the trial drug largely took place during the first two months of follow-up and no discontinuation occurred during the last six months in the placebo group.

Rebound acid secretion following discontinuation may occur [17-20]. In this study, a potential rebound effect may have been an important factor and would result in an underestimation of the proportion of participants who succeeded in a continuation of placebo. Possible tapering of PPIs would probably be more appropriate than abrupt termination. However, the study also elucidated that if symptoms do not recur within the first 60 days of PPI withdrawal they are unlikely to recur. No endoscopy was performed prior to inclusion, which might be a limitation, as patients with uninvestigated dyspepsia on long-term treatment with PPI could in principle suffer from erosive esophagitis and therefore should probably not have withheld treatment.

This is the first placebo-controlled study on discontinuation of an acid-suppressive drug in a group of long-term users, with intervention carried out in primary care, but the results are in line with those of Björnsson et al. [9], who found that discontinuation was successful in $27 \%$ of longterm users. Their patients had symptom profiles very similar to those of our patients, but patients were allocated to taper down or constant dose before discontinuation and placebo was not introduced.

A number of studies examined discontinuation of PPI but without inclusion of a placebo group. A recent study by Murie et al. [21] included patients with a diagnosis of gastroesophageal reflux disease or functional dyspepsia for prospective intervention of patient education given at specialist nurse clinic. PPI was successfully discontinued in $34 \%$ and more than half of the patients reduced the PPI dose. In a study by Krol et al. [22], GPs were randomized to give usual care or sending a simple information leaflet about dyspepsia to patients treated with PPI for at least 12 weeks. A higher discontinuation rate (24\%) was demonstrated in the intervention group, but the difference between groups did not persist after 20 weeks.

It may be objected that placebo treatment is not equivalent to absence of therapy and that $50-60 \%$ of patients with gastroesophageal reflux disease are satisfied with placebo on demand [23]. On the other hand, the perception of placebo is changing $[24,25]$ and in the present study symptoms were controlled for more than 6 months on placebo. Finally, psychological factors are of some importance in heartburn suffers [26]. Thus, on balance, it seems reasonable to consider stopping use of acid-suppressive drugs in a substantial number of long-term users without complicated peptic ulcer, severe oesophagitis, or need for protection against NSAIDs. Considerable savings could be expected if these results are applicable to the entire population of long-term users and future studies should concentrate on delineating factors predictive of successful discontinuation of proton pump inhibitors.

We recommend that symptom-based long-term antisecretory treatment in general practice should be interrupted by attempts at discontinuation. In our placebo-controlled study, nearly one-third of the patients were satisfied with placebo treatment. One in five patients treated with esomeprazole had even unsatisfactory symptom control and discontinued trial medication. Deleterious effects of antisecretory drugs have been reported $[5,27-30]$, and unnecessary treatment may lead to polypharmacy and unnecessary expenses for the patient and society. Randomised, controlled discontinuation trials, such as the study presented in this paper, are uncommon, but they may be useful in other areas of medicine (e.g., treatment with NSAIDs).

\section{Ethical Approval}

The trial was approved by the local scientific ethics committee and the Danish Data Protection Agency and was carried out in accordance with the Declaration of Helsinki. The study was monitored during planning, conduction, and analysis by the external Good Clinical Practice (GCP) unit at Odense University Hospital, Denmark.

\section{Disclosure}

The entire funding source had no involvement in the study or in the approval of the paper.

\section{Conflict of Interests}

The authors declare that there is no conflict of interests regarding the publication of this paper.

\section{Authors' Contribution}

All investigators contributed to the design, interpretation of data, and writing of the paper. Jon Eik Zwisler was the principal investigator dealing with data collection, management, and analysis. All authors have read and approved the paper.

\section{Acknowledgments}

This study was supported by grants from the Danish College of General Practitioners (the Lundbeck grant, the PLU Fund, and the MPU Fund), the County of Funen (the KAF Fund and the Foundation for Medical Science Research), Clinical Institute, University of Southern Denmark, Department of Medical Gastroenterology, Odense University Hospital, Institute of Clinical Medicine, University of Southern Denmark, the Danish Pharmacy Foundation, the Danish Research Council of Health Science, the Danish Medical Association, and the Research Unit for General Practice, Odense. AstraZeneca and DuraScan (Sandoz) supplied most of the medication for the project. 


\section{References}

[1] P. Haastrup, M. S. Paulsen, J. E. Zwisler et al., "Rapidly increasing prescribing of proton pump inhibitors in primary care despite interventions: a nationwide observational study," European Journal of General Practice, vol. 20, no. 4, pp. 290-293, 2013.

[2] A. Lødrup, C. Reimer, and P. Bytzer, "Use of antacids, alginates and proton pump inhibitors: a survey of the general Danish population using an internet panel," Scandinavian Journal of Gastroenterology, vol. 49, no. 9, pp. 1044-1050, 2014.

[3] C. Cahir, T. Fahey, L. Tilson, C. Teljeur, and K. Bennett, "Proton pump inhibitors: potential cost reductions by applying prescribing guidelines," BMC Health Services Research, vol. 12, no. 1, article 408, 2012.

[4] A. Lassen, J. Hallas, and O. B. S. de Muckadell, "Use of anti-secretory medication: a population-based cohort study," Alimentary Pharmacology \& Therapeutics, vol. 20, no. 5, pp. 577583, 2004.

[5] A. S. Raghunath, C. O'Moraint, and R. C. McLoughlin, "Review article: the long-term use of proton-pump inhibitors," Alimentary Pharmacology and Therapeutics, vol. 22, no. 1, pp. 55-63, 2005.

[6] P. Moayyedi, B. C. Delaney, N. Vakil, D. Forman, and N. J. Talley, "The efficacy of proton pump inhibitors in nonulcer dyspepsia: a systematic review and economic analysis," Gastroenterology, vol. 127, no. 5, pp. 1329-1337, 2004.

[7] J. Huang, S. K. Lam, P. Malfertheiner, and R. H. Hunt, "Has education about Helicobacter pylori infection been effective? Worldwide survey of primary care physicians," Journal of Gastroenterology and Hepatology, vol. 18, no. 5, pp. 512-520, 2003.

[8] S. V. Van Zanten, N. Flook, N. J. Talley et al., "One-week acid suppression trial in uninvestigated dyspepsia patients with epigastric pain or burning to predict response to 8 weeks' treatment with esomeprazole: a randomized, placebo-controlled study," Alimentary Pharmacology \& Therapeutics, vol. 26, no. 5, pp. 665-672, 2007.

[9] E. Björnsson, H. Abrahamsson, M. Simrén et al., "Discontinuation of proton pump inhibitors in patients on long-term therapy: a double-blind, placebo-controlled trial," Alimentary Pharmacology and Therapeutics, vol. 24, no. 6, pp. 945-954, 2006.

[10] B. Gandek, J. E. Ware Jr., N. K. Aaronson et al., “Tests of data quality, scaling assumptions, and reliability of the SF-36 in eleven countries: results from the IQOLA Project," Journal of Clinical Epidemiology, vol. 51, no. 11, pp. 1149-1158, 1998.

[11] D. A. Revicki, M. Wood, I. Wiklund, and J. Crawley, "Reliability and validity of the gastrointestinal symptom rating scale in patients with gastroesophageal reflux disease," Quality of Life Research, vol. 7, no. 1, pp. 75-83, 1998.

[12] P. Bytzer, J. M. Hansen, O. B. Schaffalitzky de Muckadell, and A. Malchow-Møller, "Predicting endoscopic diagnosis in the dyspeptic patient. The value of predictive score models," Scandinavian Journal of Gastroenterology, vol. 32, no. 2, pp. 118$125,1997$.

[13] P. C. Gotzsche, "Blinding during data analysis and writing of manuscripts," Controlled Clinical Trials, vol. 17, no. 4, pp. 285293, 1996.

[14] Annual Statistics, Danish Medicines Agency, 2015, http://dkma .medstat.dk/.
[15] D. Gaist, H. T. Sørensen, and J. Hallas, “The Danish prescription registries," Danish Medical Bulletin, vol. 44, no. 4, pp. 445-448, 1997.

[16] L. Agréus, K. Svärdsudd, O. Nyrén, and G. Tibblin, "Irritable bowel syndrome and dyspepsia in the general population: overlap and lack of stability over time," Gastroenterology, vol. 109, no. 3, pp. 671-680, 1995.

[17] C. Reimer, B. Søndergaard, L. Hilsted, and P. Bytzer, "Protonpump inhibitor therapy induces acid-related symptoms in healthy volunteers after withdrawal of therapy," Gastroenterology, vol. 137, no. 1, pp. 80.e1-87.e1, 2009.

[18] N. G. M. Hunfeld, W. P. Geus, and E. J. Kuipers, "Systematic review: rebound acid hypersecretion after therapy with proton pump inhibitors," Alimentary Pharmacology and Therapeutics, vol. 25, no. 1, pp. 39-46, 2007.

[19] A. Niklasson, L. Lindström, M. Simrén, G. Lindberg, and E. Björnsson, "Dyspeptic symptom development after discontinuation of a proton pump inhibitor: a double-blind placebocontrolled trial," American Journal of Gastroenterology, vol. 105, no. 7, pp. 1531-1537, 2010.

[20] A. B. Lodrup, C. Reimer, and P. Bytzer, "Systematic review: symptoms of rebound acid hypersecretion following proton pump inhibitor treatment," Scandinavian Journal of Gastroenterology, vol. 48, no. 5, pp. 515-522, 2013.

[21] J. Murie, J. Allen, R. Simmonds, and C. de Wet, "Glad you brought it up: a patient-centred programme to reduce protonpump inhibitor prescribing in general medical practice," Quality in Primary Care, vol. 20, no. 2, pp. 141-148, 2012.

[22] N. Krol, M. Wensing, F. Haaijer-Ruskamp et al., "Patientdirected strategy to reduce prescribing for patients with dyspepsia in general practice: a randomized trial," Alimentary Pharmacology and Therapeutics, vol. 19, no. 8, pp. 917-922, 2004.

[23] T. Lind, T. Havelund, L. Lundell et al., "On demand therapy with omeprazole for the long-term management of patients with heartburn without oesophagitis-a placebo-controlled randomized trial," Alimentary Pharmacology and Therapeutics, vol. 13, no. 7, pp. 907-914, 1999.

[24] A. Hróbjartsson and P. C. Gøtzsche, "Is the placebo powerless? Update of a systematic review with 52 new randomized trials comparing placebo with no treatment," Journal of Internal Medicine, vol. 256, no. 2, pp. 91-100, 2004.

[25] T. J. Kaptchuk, J. M. Kelley, L. A. Conboy et al., "Components of placebo effect: randomised controlled trial in patients with irritable bowel syndrome," British Medical Journal, vol. 336, no. 7651, pp. 999-1003, 2008.

[26] B. T. Johnston, J. Gunning, and S. A. Lewis, "Health care seeking by heartburn sufferers is associated with psychosocial factors," The American Journal of Gastroenterology, vol. 91, no. 12, pp. 2500-2504, 1996.

[27] Y.-X. Yang, J. D. Lewis, S. Epstein, and D. C. Metz, "Long-term proton pump inhibitor therapy and risk of hip fracture," Journal of the American Medical Association, vol. 296, no. 24, pp. 29472953, 2006.

[28] R. J. F. Laheij, M. C. J. M. Sturkenboom, R.-J. Hassing, J. Dieleman, B. H. C. Stricker, and J. B. M. J. Jansen, "Risk of community-acquired pneumonia and use of gastric acidsuppressive drugs," Journal of the American Medical Association, vol. 292, no. 16, pp. 1955-1960, 2004. 
[29] S. Dial, J. A. C. Delaney, A. N. Barkun, and S. Suissa, "Use of gastric acid-suppressive agents and the risk of communityacquired Clostridium difficile-associated disease," Journal of the American Medical Association, vol. 294, no. 23, pp. 2989-2995, 2005.

[30] P. Moayyedi and G. I. Leontiadis, "The risks of PPI therapy," Nature Reviews Gastroenterology and Hepatology, vol. 9, no. 3, pp. 132-139, 2012. 


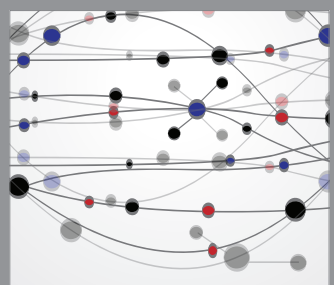

The Scientific World Journal
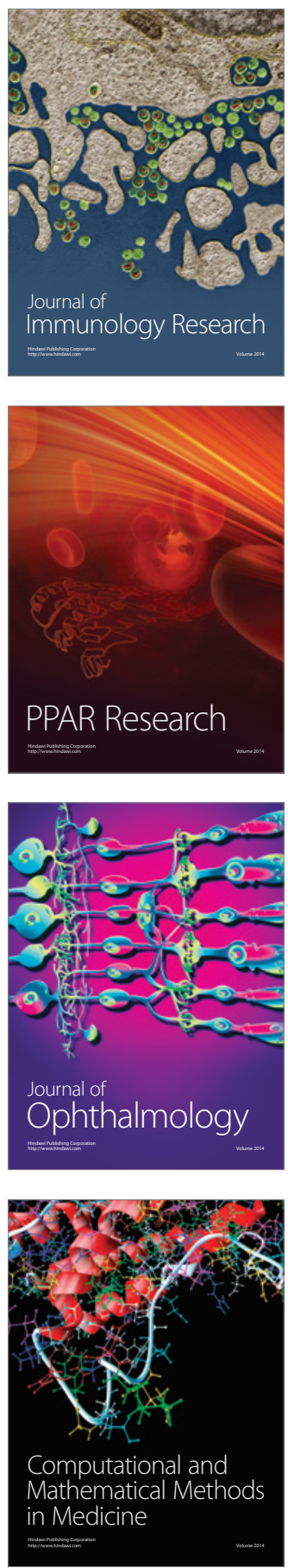

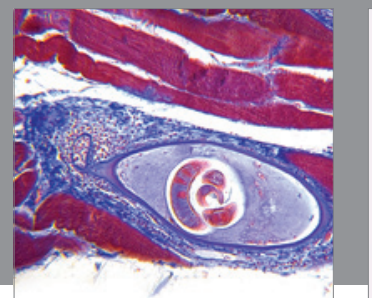

Gastroenterology

Research and Practice
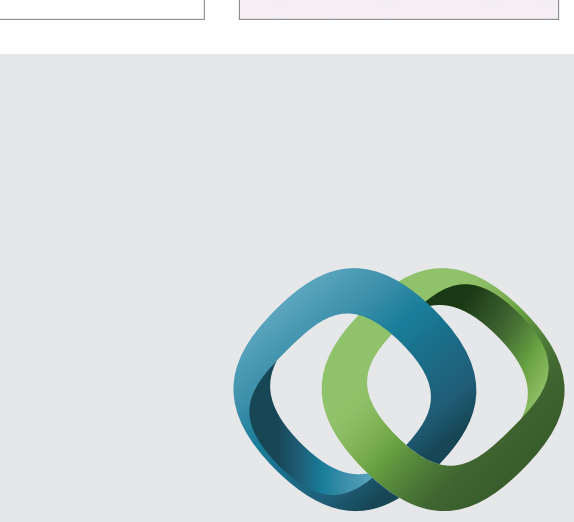

\section{Hindawi}

Submit your manuscripts at

http://www.hindawi.com
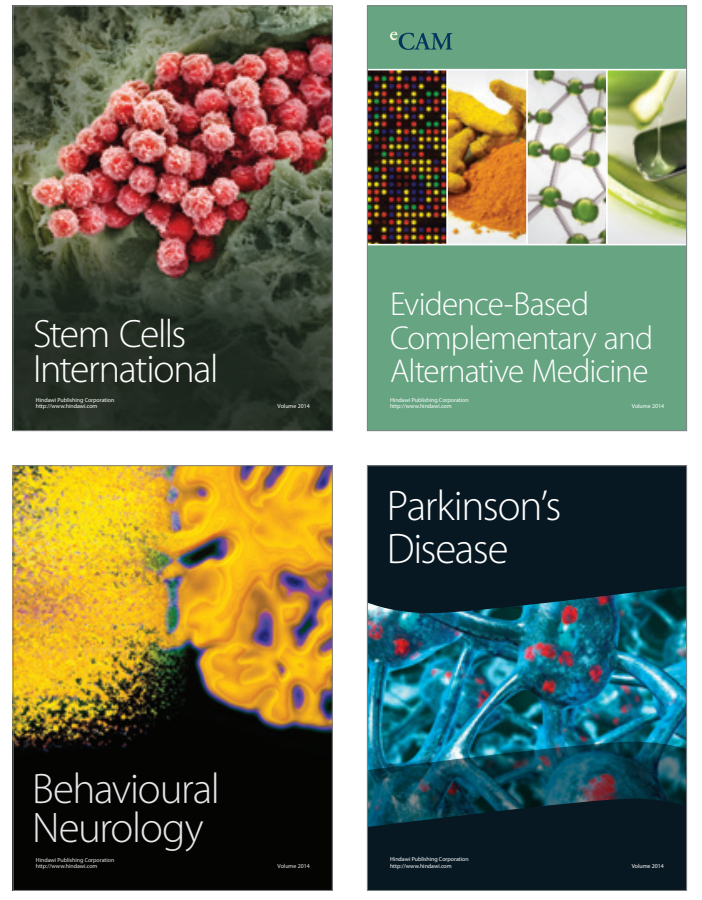
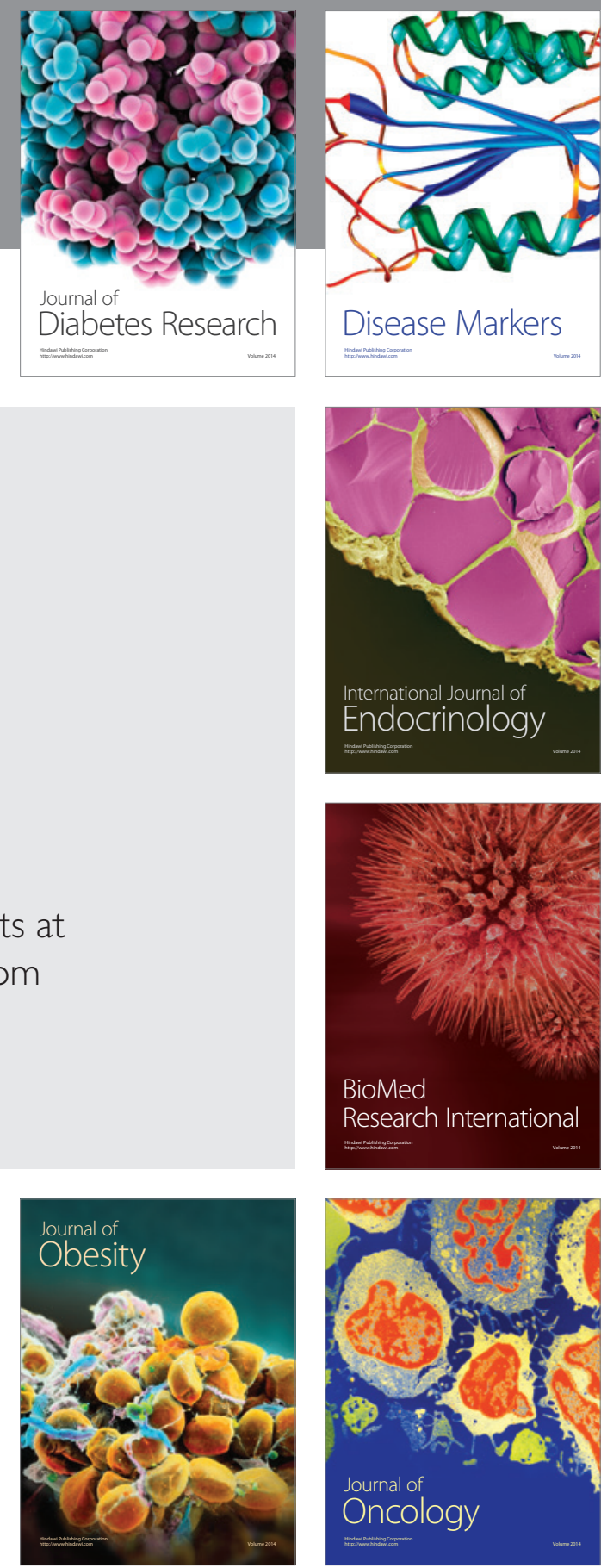

Disease Markers
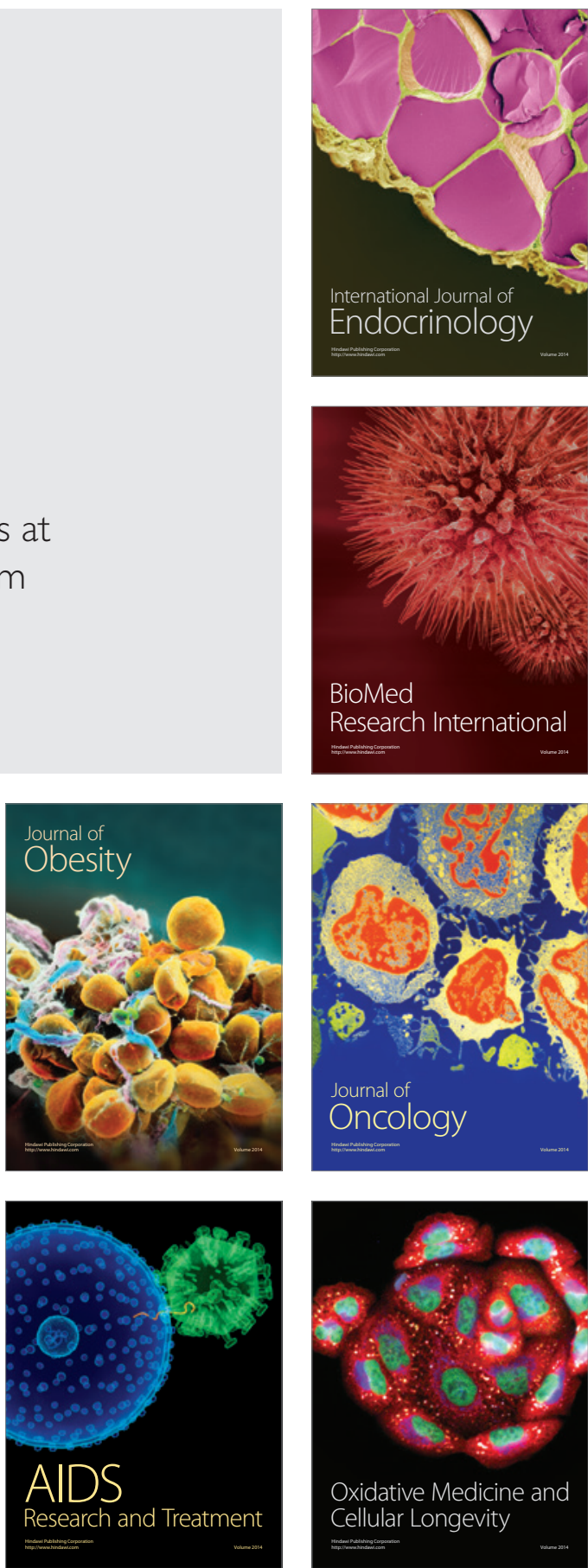